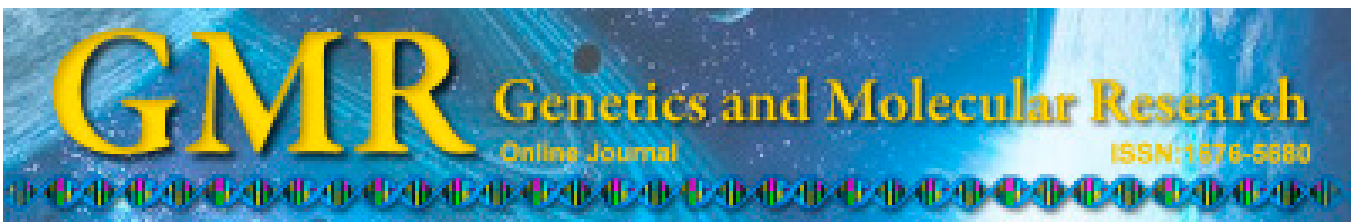

\title{
Genetic diversity in elite inbred lines of maize and its association with heterosis
}

\author{
E.H. Fernandes ${ }^{1}$, I. Schuster ${ }^{2}$, C.A. Scapim ${ }^{1}$, E.S.N. Vieira ${ }^{2}$ and \\ M.M.D. Coan ${ }^{1}$ \\ ${ }^{1}$ Departamento de Agronomia, Universidade Estadual de Maringá, \\ Maringá, PR, Brasil \\ ${ }^{2}$ Laboratório de Biotecnologia, Cooperativa Central de Pesquisa Agrícola, \\ Cascavel, PR, Brasil \\ Corresponding author: M.M.D. Coan \\ E-mail: marloncoan@gmail.com
}

Genet. Mol. Res. 14 (2): 6509-6517 (2015)

Received October 21, 2014

Accepted February 6, 2015

Published June 12, 2015

DOI http://dx.doi.org/10.4238/2015.June.12.3

\begin{abstract}
The objective of the current study was to apply molecular markers (microsatellites) in the analysis of genetic diversity of 48 lines of the elite maize germplasm stored in the bank of the Cooperativa Central de Pesquisa Agrícola - Coodetec, PR, Brazil, and estimate the correlation between genetic distance and heterosis and hybrid performance from the crosses among these maize lines. Fortyfour random primers were used and amplification of 124 polymorphic fragments was obtained. The expected findings from the correlation of the yield and heterosis with the genetic distance were non-significant. However, the results suggested that data from the extreme distances could be used in breeding for more productive crosses and heterotic hybrids. Thereby, molecular markers are efficient tools for predicting hybrid performance.
\end{abstract}

Key words: Zea mays L.; Genetic diversity; Heterotic group; Simple sequence repeat markers 


\section{INTRODUCTION}

Genetic diversity has always been estimated by maize breeders to select for the best hybrid combinations. Breeding efforts have usually been focused on promising combinations or lines that are clustered into different heterotic groups. Clustering is a method of classifying individuals based on heterosis from hybrid combinations associated with the analysis of genetic diversity.

Several methods have been described to evaluate genetic diversity. In maize, the use of molecular markers to help the conventional methodologies has been very important for evaluation of genetic diversity of the lines and in clustering the heterotic groups. These markers are used to estimate genetic diversity of maize lines by clustering methods based on their genetic similarity. Clustering relates the heterotic groups selecting the most promising crosses, thereby reducing both the number of crosses and the number of hybrids under evaluation (Guimarães et al., 2007).

Laborda et al. (2005) stated that the estimates of genetic divergence between the lines evaluated by molecular markers have reduced the manual labor involved in pollination, have clustered heterotic groups, and have directed breeding to obtain the most productive and vigorous hybrids. Several maize breeders have researched the correlation between the genetic diversity quantified by molecular markers of DNA and the performance of hybrids, but the results have been incongruous. For example, Smith et al. (1990) pointed out a positive relationship between the genetic distance from the progenitors and the performance of the F1 plants when the sample size and the number of molecular markers were simultaneously amplified. Stuber et al. (1992) reported significant correlation between progenitor heterozygosity and crop yield in hybrids when the number of endogamic progenitor lines was also increased. Based on the results reported by Lanza et al. (1997), crop yield in maize was found to be positively correlated with genetic distance estimated by random amplified polymorphic DNA (RAPD) markers. In contrast, Barbosa-Neto et al. (1996) did not find any relationship between molecular markers and hybrid performance in wheat.

Gadheri et al. (1984) found that the dominance or the epistasis effect involving dominance is necessary for positive association of genetic divergence with heterosis. Furthermore, the parentage must be different in terms of the allelic frequency controlling the plant characteristic under study. These differences must increase with the divergence from the parents, allowing the manifestation of dominant effects and, therefore, increasing the heterosis. Bruel et al. (2006) and Guimarães et al. (2007) found a direct relationship between genetic divergence of maize lines and hybrid yield, sustaining the hypothesis that genetic divergence of the lines is directly related to the hybrid performance and is efficient in predicting their responses.

The simple sequence repeats (SSRs) have been widely applied to evaluate genetic diversity in maize (Smith et al., 1997; Pinto et al., 2003; Reif et al., 2003; Adetimirin et al., 2008; Warburton et al., 2008; Kuroda et al., 2009). Terra et al. (2011) and Adeyemo et al. (2011) also reported the efficiency of microsatellite markers in studies of genetic diversity. However, even highly polymorphic molecular markers allow for negative correlation of genetic diversity with heterosis, which is explained by the absence of dominance, the fact that allelic frequencies of parental lines are not negatively correlated, the fact that markers are not associated with a quantitative trait locus (QTL) for the character, and because the productivity does not have high heritability. Charcosset et al. (2001) stated that the heterosis prediction of F1 hybrids 
based on molecular markers is more efficient if the selected markers were associated with the character under study because the markers without links to character loci can dilute the relation of heterosis with heterozygosity.

Studies on the relation of genetic diversity within maize lines and performance of their hybrids have always been carried out with the temperate germplasm. The objective of the current study was to apply microsatellite molecular markers to evaluate the genetic diversity within a cluster of 48 tropical lines of maize in Brazil and associate their diversity with the heterosis and productivity of their respective hybrids.

\section{MATERIAL AND METHODS}

We evaluated 48 lines from the maize breeding program of the Coodetec and 224 hybrids from these lines. Heterotic groups from these 48 endogamic lines were first defined using topcross trials from previous growing seasons carried out at the research center of the Coodetec, Cascavel County, PR, Brazil. The 48 lines and their hybrids were sown manually in November 2009, in plots of four rows $5 \mathrm{~m}$ long and spaced at $0.8 \mathrm{~m}$, by seeding two seeds per hole; the holes were in line spaced at $0.20 \mathrm{~m}$. The experimental design was completely randomized blocks with two replications. The hybrid trial with 224 simple hybrids that were obtained with the combination between the lines of the distinct heterotic groups was carried out without replication and environmental control. The grain productivity reported in $\mathrm{kg} / \mathrm{ha}$ for each hybrid and each line was adjusted to the moisture of $13 \%$. The heterosis was calculated by subtracting the average productivity of parental lines from hybrid productivity.

In order to analyze genetic diversity using molecular markers, DNA extraction was performed as described in Doyle and Doyle (1990) and PCR was carried out with 44 randomly chosen microsatellite markers. DNA was extracted from leaf samples from 10 plants of each strain and quantified by absorbance at $260 \mathrm{~nm}$ in a spectrophotometer Nanodrop1000 (NanoDrop Products, Wilmington, DE, USA). The samples were diluted to a final concentration of $6 \mathrm{ng} / \mu \mathrm{L}$. Amplification of the SSRs followed the PCR touch-down program consisting of an initial step of $5 \mathrm{~min}$ at $94^{\circ} \mathrm{C}$ followed by 10 cycles each of $1 \mathrm{~min}$ at $94^{\circ} \mathrm{C}, 1 \mathrm{~min}$ at $65^{\circ} \mathrm{C}$ (decreasing $1{ }^{\circ} \mathrm{C}$ every cycle), and $1 \mathrm{~min}$ and $30 \mathrm{~s}$ at $72^{\circ} \mathrm{C}$. This was followed by another 30 cycles each of $1 \mathrm{~min}$ at $94^{\circ} \mathrm{C}, 1 \mathrm{~min}$ at $55^{\circ} \mathrm{C}$, and $30 \mathrm{~s}$ at $72^{\circ} \mathrm{C}$ and a final step of $5 \mathrm{~min}$ at $72^{\circ} \mathrm{C}$. PCR products were separated with electrophoresis on $4 \%$ agarose gels stained with ethidium bromide for $2 \mathrm{~h}$ at $210 \mathrm{~V}$ and visualized under UV light (Vilber Lourmat, Marne-la-Vallée Cedex 1, France).

The genetic diversity from every microsatellite locus was calculated by using the allele frequency and genetic distance from the similarity index complement of the coefficient of simple coincidence for the co-dominant and multiallelic data using the Genes software (Cruz, 2001). This index was calculated by dividing the total number of common alleles of two lines by the total number of alleles.

The following formula was used: $\mathrm{S}=\mathrm{N} / 2 \mathrm{~L}$, where $\mathrm{S}$ is the similarity index, $\mathrm{N}$ is the number of common alleles, and $\mathrm{L}$ is the number of loci analyzed. The total number of alleles for each individual is twice the number of loci analyzed, since each individual has two alleles at each locus. The dissimilarity index (D) was given as: $\mathrm{D}=1-\mathrm{S}$. Based on the matrix of genetic distances, the lines were clustered by the unweighted pair group method with arithmetic mean (UPGMA) using the STATISTICA software (Statsoft Inc., 1999). 


\section{RESULTS}

The molecular characterization of 48 maize lines using 44 microsatellite primers yielded 124 polymorphic alleles with the average of 2.8 alleles per locus. The level of polymorphism was similar to those reported by Wiethölter et al. (2008), who detected 2.7 alleles per locus in the analysis of 33 microsatellite loci in maize, and Le Clere et al. (2005), who analyzed 133 maize cultivars using 51 microsatellite loci and obtained 2.9 alleles per locus on average. In contrast, in the studies by Menkir et al. (2004), Adeyemo et al. (2011), and Terra et al. (2011), the number of alleles ranged from 3.7 to 5.7 per locus. These authors attributed such high polymorphism to the level of divergence found within the genotypes evaluated in conjunction with the pre-selection of the primers that was based on the number and quality of the amplification products.

The polymorphism information content (PIC) values from the 44 microsatellite loci ranged from 0.04 (Bnlg1350) to 0.71 (Umc1005), with the average PIC of 0.42 (Table 1). Since PIC is an estimate of the marker's discriminatory strength and is synonymous with genetic diversity, the results indicated that the 48 lines analyzed with 44 primers had high genetic variability. These values are similar to the results reported by Aguiar et al. (2008) (PIC values 0.05-0.66; average, 0.51 ) from 44 maize lines analyzed with 28 microsatellite primers. Similar results were observed by Amorim and Souza (2005) and Bered et al. (2005) in sweet corn and by Patto et al. (2004) and Terra et al. (2011) using commercial lines of maize.

\begin{tabular}{|c|c|c|c|c|c|c|c|}
\hline Primer & "Bin" & Allele No. & PIC & Primer & "Bin" & Allele No. & PIC \\
\hline umc1071 & 1.01 & 3 & 0.56 & bnlg 105 & 5.02 & 3 & 0.54 \\
\hline bnlg 109 & 1.02 & 2 & 0.05 & bnlg1208 & 5.03 & 3 & 0.48 \\
\hline bnlg1811 & 1.04 & 2 & 0.36 & umc1019 & 5.06 & 4 & 0.7 \\
\hline umc1035 & 1.06 & 3 & 0.48 & bnlg161 & 6.00 & 4 & 0.39 \\
\hline mmc0041 & 1.08 & 3 & 0.53 & $\mathrm{mmc} 0241$ & 6.05 & 3 & 0.4 \\
\hline umc1797 & 1.12 & 4 & 0.69 & umc1653 & 6.07 & 5 & 0.62 \\
\hline bnlg125 & 2.02 & 3 & 0.57 & umc1016 & 7.02 & 4 & 0.56 \\
\hline bnlg1045 & 2.07 & 3 & 0.6 & umc1015 & 7.03 & 3 & 0.49 \\
\hline mmc0191 & $2.07 / 2.08$ & 4 & 0.56 & bnlg155 & 7.04 & 2 & 0.16 \\
\hline bnlg1338 & 2.01 & 3 & 0.57 & umc1359 & 8.00 & 2 & 0.16 \\
\hline dup24 & 2.08 & 3 & 0.4 & umc1786 & 8.01 & 2 & 0.08 \\
\hline mmc0312 & 3.04 & 3 & 0.32 & bnlg669 & 8.03 & 2 & 0.21 \\
\hline bnlg1350 & 3.08 & 2 & 0.04 & bnlg1031 & 8.06 & 3 & 0.51 \\
\hline bnlg2241 & 3.06 & 2 & 0.35 & umc1005 & 8.08 & 4 & 0.71 \\
\hline umc1136 & 3.10 & 3 & 0.6 & dup14 & 8.09 & 2 & 0.34 \\
\hline umc 1008 & 4.00 & 3 & 0.5 & bnlg1724 & 9.00 & 2 & 0.34 \\
\hline phi026 & 4.05 & 2 & 0.08 & umc1033 & 9.02 & 4 & 0.63 \\
\hline bnlg2291 & 4.07 & 2 & 0.34 & phi061 & 9.03 & 3 & 0.49 \\
\hline $\mathrm{mmc} 0321$ & 4.08 & 3 & 0.4 & umc1771 & 9.04 & 2 & 0.16 \\
\hline umc1101 & 4.09 & 2 & 0.08 & bnlg 1588 & 9.07 & 4 & 0.54 \\
\hline bnlg589 & 4.11 & 2 & 0.36 & bnlg1129 & $9.07 / 9.08$ & 2 & 0.08 \\
\hline bnlg1006 & 5.00 & 2 & 0.7 & bnlg153 & $10.06 / 10.07$ & 2 & 0.33 \\
\hline Total & & & & & & 124 & \\
\hline Average & & & & & & 2.8 & 0.42 \\
\hline
\end{tabular}

The clustering analysis based on the genetic distance matrix resolved three groups of lines. The average genetic distance between the lines was 0.52 , with the lowest value of 0.27 (LIN-30 x LIN-31) and the highest of 0.67 (LIN-25 x LIN-38). The amplitude was small. The 
highest frequency ranged from 0.4 to 0.6 (Figure 1), indicating small variability between these lines. Adeyemo et al. (2011) reported an average distance of 0.45 for the hybrids, and Bruel et al. (2006) found that the distance between the pairs of pure lines ranged from 0.27 to 0.64 , the average of 0.51 , in 120 hybrids.

The line clustering was analyzed using data for genetic diversity inferred from the microsatellites. In the dendrogram, the UPGMA analysis resolved three groups of lines (Figure 2).

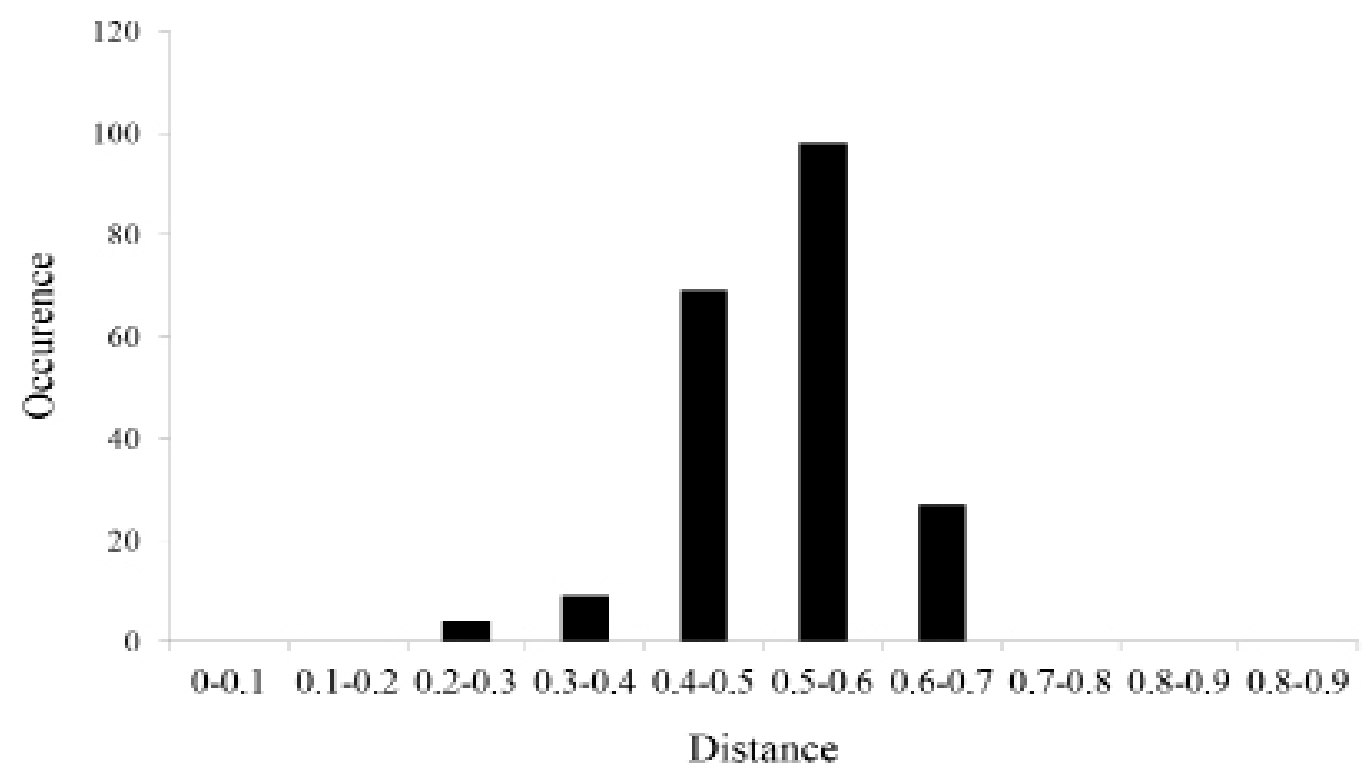

Figure 1. Distribution of the distance amid the lines.

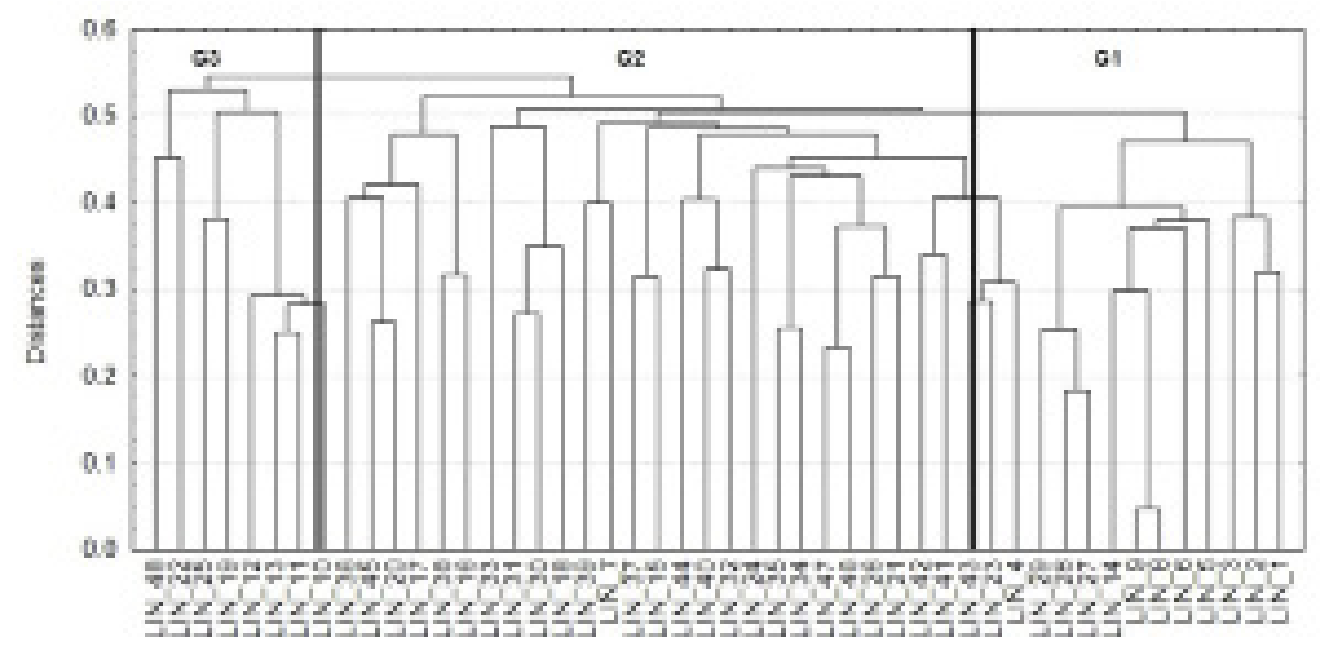

Figure 2. Clustering analysis of 48 maize lines using the UPGMA method from the genetic distance matrix of the molecular data. 
The value of the cophenetic correlation $(r=0.59)$ indicated concordance with the genetic distance values and, thus, the reliability of the dendrogram. Guimarães (2007), in his study of the genetic divergence of molecular markers, found similar correlation $(\mathrm{r}=0.57)$, and Patto et al. (2004) stated that correlation higher than 0.56 is the optimal value. Reif et al. (2003), who genotyped 20 maize populations using 83 microsatellites, found that genetic distance correlated with heterosis data from the diallel crossing between these populations. Two groups were formed, and the correlation values ranged from 0.18 to 0.56 .

In the current experiment, the estimates of heterosis ranged from $611.5 \mathrm{~kg} / \mathrm{ha}$ (LIN$32 \times$ LIN-14) to $9317.0 \mathrm{~kg} / \mathrm{ha}$ (LIN-47 x LIN-14), corroborating the large genetic variability in the specific recombination capacity of these lines. The average productivity and heterosis were higher between lines of the same cluster (Figure 3). Thus, correlation was not observed between the genetic distance and heterosis or between the genetic distance and productivity of hybrids. Similar results were found by Guimarães et al. (2007), who correlated heterosis with genetic divergence in maize lines.

In Figure 4, the genetic distance of 0.51 clustered the data in two groups of the same size. However, among the three more heterotic hybrids (above $9.000 \mathrm{~kg} / \mathrm{ha}$ ), two had genetic distance higher than 0.51. Similar results were found for the productivity, indicating that the choice of the extreme genetic distance from these molecular markers can guide the work of the plant breeder because, on crossing just $50 \%$ of them, the most productive and heterotic hybrids would be produced. Thus, the best hybrid would be identified using cost-effective labor, showing the efficiency of molecular markers in studies of genetic divergence.

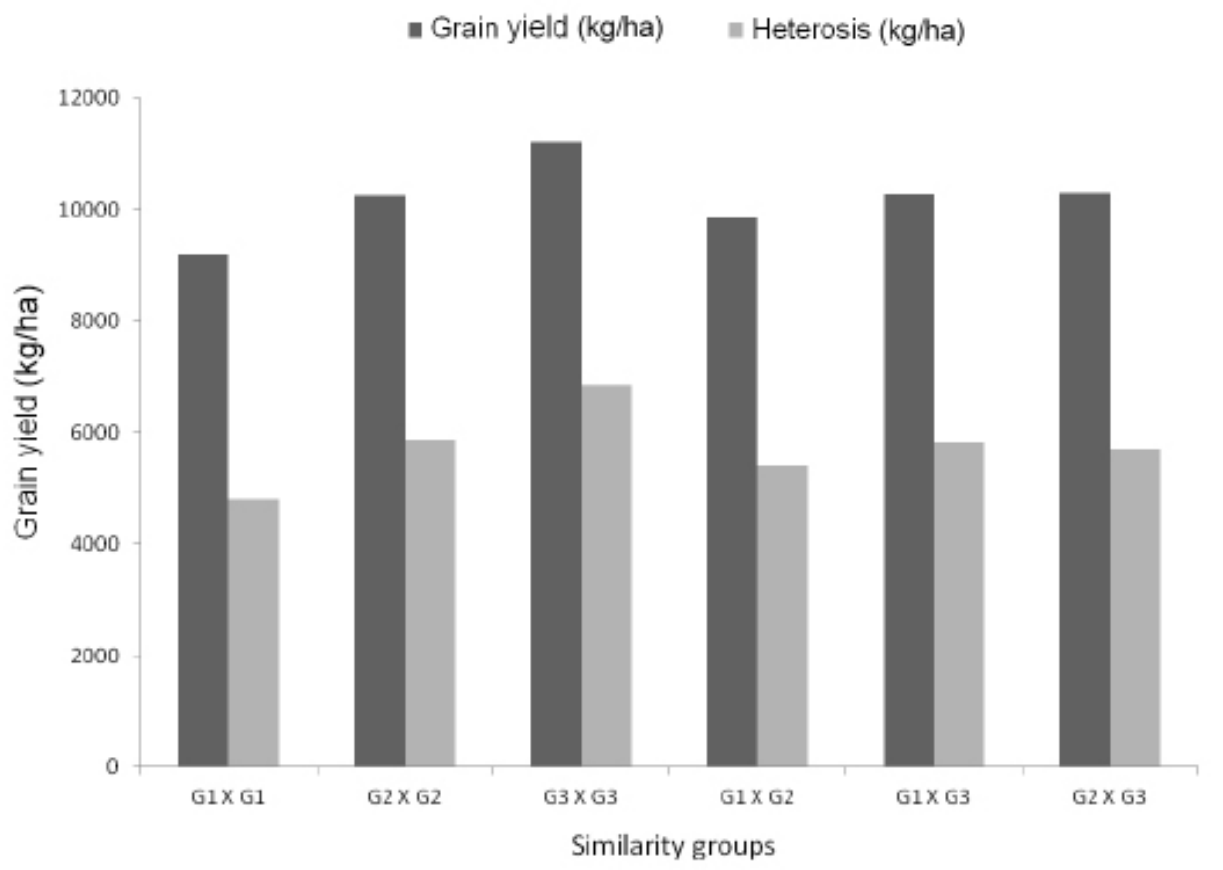

Figure 3. Average of grain yield and heterosis of the lines from the different groups of similarity. 



Figure 4. A. Genetic distance in relation to the heterosis amid the lines. B. Genetic distance in relation to the grain yield of the lines.

\section{DISCUSSION}

The negative correlation can be found because the markers may not be associated with the QTLs that determine the character or because the productivity is not highly heritable (Lanza et al., 1997). Similar results were found by Guimarães et al. (2007), who correlated heterosis with genetic divergence in maize lines. These authors stated that the hybrid with the highest heterosis was crossed using lines from different heterotic groups, unlike the hybrids with the lowest values that were crossed with the lines of the same group. The genetic divergence, however, was not enough to determine the specific combining ability and the hybrids 
yield.

Thus, to achieve the highest efficiency in predicting the hybrid responses is to select markers associated with QTLs previously mapped for grain productivity. In Brazil, Parentoni et al. (2001) evaluated 378 maize hybrids from 28 varieties of open pollination in 10 environments. These varieties were genotyped with 50 RAPD markers to correlate the specific capacity of combination with the genetic distance within the progenitors, but the correlation was low. These authors stated that this low correlation was likely associated with the use of markers without linking to the QTLs for grain productivity.

In maize, several reports have indicated correlation of the parental genetic distance and hybrid performance, although it differed in magnitude (Melchinger et al., 1999; Benchimol et al., 2000; Barbosa et al., 2003; Bruel et al., 2006; Adeyemo et al., 2011). Knowledge regarding the genetic divergence in the main tropical lines of maize used in genetic breeding programs in Brazil is limited and has indicated the importance of studying genetic divergence of the national germplasm banks. According to Guimarães (2007), the clustering of heterotic group adequate for hybrid program has been difficult because of the lack of information. Furthermore, large quantity of tropical maize populations in breeding programs comes from different populations and composites, with a large genetic base and higher variability than the temperate germplasm. Sibov et al. (2003) stated that these factors may limit direct application of QTLs from temperate germplasm to the tropical breeding programs.

However, molecular markers have allowed significant insights into the research of genetic divergence of maize (Smith et al., 1990; Lanza et al., 1997; Benchimol et al., 2000; Barbosa et al., 2003; Oliveira et al., 2004; Laborda et al., 2005; Bruel, 2006; Aguiar, 2008). The divergence of lines evaluated by molecular markers may reduce significantly the labor involved in pollination and make possible to obtain heterotic groups with further allotting of new lines in these groups and guiding the crosses to obtain the most productive hybrids.

The current results suggest that the correlation of genetic distance and heterosis with maize productivity based on molecular markers is more efficient if the markers are selected based not only on their location in the genome, allele frequency, and PIC, but also on their linkage to the QTLs of productivity.

However, the current experiments suggest that the extreme distances between the molecular markers could direct the breeding because even if the crosses are done with only the half of the hybrids, the most productive and heterotic ones would have been produced, indicating that molecular markers are good predictors of the hybrid performance.

\section{REFERENCES}

Adetimirin VO, Vroh-Bi I, The C, Menkir A, et al. (2008). Diversity analysis of elite maize inbred lines adapted to west and central Africa using SSR markers. Maydica 53: 143-149.

Adeyemo O, Menkir A, Melaku G and Omidiji O (2011). Genetic diversity assessment and relationship among tropicalyellow endosperm maize inbred lines using SSR markers. Maydica 56: 17-23.

Aguiar CG, Schuster I, Amaral AT Jr, Scapim CA, et al. (2008) Heterotic groups in tropical maize germplasm by test crosses and simple sequence repeat markers. Genet. Mol. Res. 7: 1233-1244.

Amorim EP and Souza JC (2005). Evaluation of inter and intrapopulation maize hybrids from $\mathrm{S}_{0}$ progenies of commercial single cross hybrids. Bragantia 64: 561-567.

Barbosa AMM, Geraldi IO, Benchimol LL, Garcia AAF, et al. (2003). Relationship of intra-and interpopulation tropical maize single cross hybrid performance and genetic distances computed from AFLP and SSR markers. Euphytica 130: 87-99.

Barbosa-Neto JF, Sorrells ME and Cisar G (1996). Prediction of heterosis in wheat using coefficient of parentage and 
RFLP-based estimates of genetic relationship. Genome 39: 1142-1149.

Benchimol LL, Souza CL Jr, Garcia AAF, Kono PMS, et al. (2000). Genetic diversity in tropical maize inbred lines: heterotic group assignment and hybrid performance determined by RFLP markers. Plant Breed. 119: 491-496.

Bered F, Terra TF, Spellmeier M and Barbosa Neto JF (2005). Genetic variation among and within sweet corn populations detected by RAPD and SSR markers. Crop Breed. Appl. Biot. 5: 418-425.

Bruel C, Carpentieri-Pípolo V, Gerage AC, Fonseca NS Jr, et al. (2006). Genetic distance estimated by RAPD markers and its relationship with hybrid performance in maize. Pesq. Agropec. Bras. 41: 1491-1498.

Charcosset A, Lefort-Buson M and Gallais A (2001). Relationship between heterosis and heterozygosity at marker loci: a theoretical computation. Theor. Appl. Genet. 81: 571-575.

Cruz CD (2006). Programa GENES - Análise multivariada e simulação. 1st edn. Universidade Federal de Viçosa, Viçosa.

Doyle JJ and Doyle JL (1990). Isolation of plant DNA from fresh tissue. Focus 12: 13-15.

Gadheri A, Adans MW and Nassib AM (1984). Relationship between genetic distance and heterosis for yield and morphological traits in dry edible bean and faba bean. Crop Sci. 24: 37-42.

Guimarães SP, Paterniani MEAGZ, Lüders RR, Souza AP, et al. (2007). Correlation between the heterosis of maize hybrids and genetic divergence among lines. Pesq. Agropec. Bras. 42: 811-816.

Kuroda Y, Tomooka N, Kaga A, Wanigadeva SMSW, et al. (2009). Genetic diversity of wild soybean (Glycine soja Sieb. et Zucc.) and Japanese cultivated soybeans [G.max (L.) Merr.] based on microsatellite (SSR) analysis and the selection of a core collection. Genet. Resour. Crop Evol. 56: 1045-1055.

Laborda PR, Oliveira KM, Garcia AAF, Paterniani MEAGZ, et al. (2005). Tropical maize germoplasm: what can we say about its genetic diversity in the light of molecular markers? Theor. Appl. Genet. 111: 1288-1299.

Lanza LLB, Souza CL Jr, Ottoboni LMM, Vieira MLC, et al. (1997). Genetic distance of inbred lines and prediction of maize single-cross performance using RAPD markers. Theor. Appl. Genet. 94: 1023-1030.

Le Clere V, Bazante F, Baril C, Guiard J, et al. (2005). Assessing temporal changes in genetic diversity of maize varieties using microsatellite markers. Theor. Appl. Genet. 110: 294-302.

Melchinger AE, Messmer MM, Lee M, Woodman WL, et al. (1999). Diversity and relationships among U.S. maize inbreds revealed by restriction fragment lenght polymorphisms. Crop Sci. 31: 669-678.

Menkir A, Melake-Berhan A, The C, Ingelbrecht I, et al. (2004). Grouping of tropical mid-altitude maize inbred lines on the basis of yield data and molecular markers. Theor. Appl. Genet. 108: 1582-1590.

Oliveira KM, Laborda PR, Garcia AAF, Paterniani ZME, et al. (2004). Evaluating genetic relationships between tropical maize inbred lines by means of AFLP profiling. Hereditas 140: 24-33.

Parentoni SN, Magalhães JV, Pacheco CAP, Santos MX, et al. (2001). Heterotic groups based on yield-specific combining ability data and phylogenetic relationship determined by RAPD markers for 28 tropical maize open pollinated varieties. Euphytica 121: 197-208.

Patto MCV, Satovic Z, Pêgo S and Fevereiro P (2004). Assessing the genetic diversity of Portuguese maize germplasm using microsatellite markers. Euphytica 137: 63-72.

Pinto LR, Vieira MLC, de Souza CL and Souza AP (2003). Genetic-diversity assessed by microsatellites in tropical maize populations submitted to a high-intensity reciprocal recurrent selection. Euphytica 134: 277-286.

Reif JC, Melchinger AE, Xia XC, Warburton ML, et al. (2003). Genetic distance based on simple sequence repeats and heterosis in tropical maize populations. Crop Sci. 43: 1275-1282.

Sibov ST, Souza CL Jr, Garcia AA, Garcia AF, et al. (2003). Molecular mapping in tropical maize (Zea mays L.) using microsatellite markers. 1. Map construction and localization of loci showing distorted segregation. Hereditas 139: 96-106.

Smith JSC, Chin ECL, Shu H, Smith OS, et al. (1997). An evaluation of the utility of SSR loci as molecular markers in maize (Zea mays L): Comparisons with data from RFLPs and pedigree. Theor. Appl. Genet. 95: 163-173.

Smith OS, Smith JSC, Bowen SL, Tenborg RA, et al. (1990). Similarities among a group of elite maize inbreds as measured by pedigree, F1 grain yield, grain yield, heterosis, and RFLPs. Theor. Appl. Genet. 80: 833-840.

Stuber CW (1992). Heterosis in plant breeding. In: Plant breeding reviews. Volume 12 (Janick J, ed.). 227-225.

Terra TF, Wiethölter P, Almeida CCS, Silva SDA, et al. (2011). Genetic variability in maize and teosinte populations estimated by microsatellites markers. Cienc. Rural 4: 205-211.

Warburton ML, Reif JC, Frisch M, Bohn M, et al. (2008). Genetic diversity in CIMMYT nontemperate maize germplasm: landraces open pollinated varieties, and inbred lines. Crop Sci. 48: 617-624.

Wiethölter P, Sereno MJCM, Terra TF, Silva SDA, et al. (2008). Genetic variability in corn landraces from Southern Brazil. Maydica 53: 151-159. 